\title{
Medical Practice Differences Among Internal Medicine Fellows During in-hospital Emergency Department 24-hour Shifts
}

\author{
Marina Repusic \\ Institute For Transfusion Medicine
}

Matea Kolacevic Zeljkovic

Klinicki bolnicki centar Sestre milosrdnice

\section{Alen Babacanli}

Klinicki bolnicki centar Sestre milosrdnice

Vida Olujic

Klinicki Bolnicki Centar Split

\section{Sandra Radovanic}

Klinicki Bolnicki Centar Split

\section{Aljosa Sikic}

Klinicki bolnicki centar Sestre milosrdnice

Vjekoslav Radeljic

Klinicki bolnicki centar Sestre milosrdnice

Nikola Bulj

Klinicki bolnicki centar Sestre milosrdnice

Nikola Pavlovic

Klinicki bolnicki centar Sestre milosrdnice

Kristijan Dula

Klinicki bolnicki centar Sestre milosrdnice

\section{Sime Manola}

Klinicki bolnicki centar Sestre milosrdnice

ivan zeljkovic ( $\boldsymbol{D}$ ivanzeljkov@gmail.com )

Department of Cardiology, Sestre milosrdnice University Hospital Centre, Zagreb, Croatia https://orcid.org/0000-0002-4550-4056

\section{Research article}

Keywords: emergency department, practice, fellow, fellowship, internal medicine, difference

Posted Date: August 26th, 2020 
DOI: https://doi.org/10.21203/rs.3.rs-54661/v1

License: (c) (1) This work is licensed under a Creative Commons Attribution 4.0 International License. Read Full License 


\section{Abstract}

Background There are limited data which show how Emergency Department (ED)-specific knowledge and skills are acquired throughout the internal medicine fellowship, especially during 24-hour shifts. The aim of the study was to assess the differences in medical practice between fellows among different fellowship-years in ED settings.

Methods We conducted a cross-sectional, retrospective study at a large university hospital using data on every ED examination done during 2016. All data were taken from the hospital information system. We compared $1^{\text {st }}$-year fellows with all older fellows, as well as $5^{\text {th }}$-year fellows with all younger fellows.

Results In 2016, 55 fellows had $\geq 15$ 24-hour shifts with 3 attending fellows during one shift. A total of $19^{\prime} 916$ patients were examined by attending fellows in the ED. When compared to $2^{\text {nd }}-$ year fellows, $1^{\text {st }}$ year fellows examined more patients brought to ED by out-of-hospital emergency medical team and had significantly higher share of examined patients per 24-hour shift with lower length of stay. When compared to $5^{\text {th }}$-year fellows, $1^{\text {st }}$-year fellows examined older patients, but had lower share of examined patients during one 24-hour shift and participated in fewer CPR cases. When compared to younger fellows, $5^{\text {th }}$-year fellows participated in more CPR cases and had higher proportion of patients admitted to hospital.

Conclusion To our knowledge, this is the first report on the ED medical practice differences among fellows of different fellowship-year. When compared to other fellows, $1^{\text {st }}$-year fellows participated less in CPR cases, but were faster in providing medical care in ED. $5^{\text {th }}$-year fellows had the highest proportion of patients admitted to hospital and more CPR cases.

\section{Background}

24-hour shifts in the Emergency Department (ED) are one of the components of internal medicine fellowship in Croatia, which includes obligatory 5 year of structured mostly clinical education with graduate-exam at the end [1]. An ED environment of mostly undifferentiated patients demands high clinical-diagnostic knowledge, manual skills as well as communication and organizational skills [2-4]. It also demands fast learning and quick adjustment, with more experienced fellows developing special routines that allow them to flexibly adapt to less common circumstances [2,3,5-7]. However, there are limited data which show how ED-specific knowledge and skills are acquired throughout the internal medicine fellowship, especially during 24-hour shifts which are physically exhausting and psychologically very stressful [6,7]. The aim of the study was to assess the differences in medical practice between fellows among different fellowship-years in ED settings. We hypothesized that $1^{\text {st }}$-year fellows (novices) are slower in providing ED medical care when compared to older fellows.

\section{Methods}


We conducted a cross-sectional, retrospective study at a large university hospital. Data on every ED examination done by internal medicine fellows in the ED during 2016 (January $1^{\text {st }}$-December $31^{\text {st }}$ ) were analysed. All data were taken from the hospital information system. We compared $1^{\text {st }}$-year fellows with $2^{\text {nd }}$-year fellows, $5^{\text {th }}$-year fellows and all older fellows altogether, as well as $5^{\text {th }}$-year fellows with all younger fellows. We assessed baseline patients' characteristics plus mobility, verbal communication capacity and level of consciousness, as well as time spent in the ED and the proportion of all patients examined per 24-hour shift for a particular fellowship-year. In addition, patients' arrival arrangement, decision on hospital admittance, cardiopulmonary resuscitation (CPR) cases and death cases were analysed. Descriptive statistics were presented as absolute values and percentages, or means and standard deviations. Statistical test for categorical and continuous variables were used where appropriate, using SPSS-Version 20 (IBM, New York, USA). The hospital's Ethics Committee gave its approval for the study, which was conducted in accordance with the Declaration of Helsinki.

\section{Results}

In 2016, 55 fellows had $\geq 15$ 24-hour shifts with 3 attending fellows during one shift and most shifts included one 1st-year fellow and one 5th-year fellow. A total of 19'916 patients were examined by attending fellows in the ED. When compared to $2^{\text {nd }}$-year fellows, $1^{\text {st }}$-year fellows examined more patients brought to ED by out-of-hospital emergency medical team (EMT) and had significantly higher share of examined patients per 24-hour shift with lower length of stay (LOS). When compared to $5^{\text {th }}$-year fellows, $1^{\text {st }}$-year fellows examined older patients and more often those brought by EMT, but had lower share of examined patients during one 24-hour shift and participated in fewer CPR cases, which was also the case when compared to all older fellows. When compared to younger fellows, $5^{\text {th }}$-year fellows participated in more CPR cases and had higher proportion of patients admitted to hospital. The comparison between $1^{\text {st }}$ year fellows and 5th-year fellows, $2^{\text {nd }}$-year fellows and all older fellows is given in Table 1, 2 and 3, and the comparison of $5^{\text {th }}$-year fellows with all younger fellows in Table 4.

\section{Discussion}

To our knowledge, this is the first report on the ED medical practice differences among fellows of different fellowship-year. The main findings are the following: 1) when compared to other fellows, $1^{\text {st }}$-year fellows participated less in CPR cases; 2) $1^{\text {st }}$-year fellows had higher proportion of examined patients per 24-hour shift when compared to $2^{\text {nd }}$-year fellows and lower when compared to $5^{\text {th }}$-year fellows; 3 ) $5^{\text {th }}$-year fellows had the highest proportion of patients admitted to hospital.

Nowadays, in times of continuous ED overcrowding, there are increasing efforts to reduce ED LOS while continuously improving patients' management [3,4,8-10]. Our study suggests that, although 24-hour ED shifts offer very stressful and exhaustive experience and demand high-developed ED-specific skills $[2,3,5,7,9-11], 1$ st-year fellows adapt rather quickly. They were not slower in providing ED medical care when compared to older colleagues, except when compared to exclusively $5^{\text {th }}$-year fellows. In addition, 
that $5^{\text {th }}$-year fellows were able to exam more acute and complicated patients in comparison to ${ }^{\text {st }}$-year fellows with no significant difference in LOS per patient. Everything mentioned is only partially in line with the literature findings on other medical specialties in which older fellows become more efficient both in terms of acuity of the patients as well as LOS shortening [2,12-15]. However, in ED environment the workspeed is influenced by many factors, not just by fellow's experience. However, the broader repertoire of specific routines developed towards the end of their fellowship, helps 5th-year fellows to gain determination and confidence to participate in CPR cases and to make decisions on hospital admittance more freely and decisively[3,16-19]. Moreover, it would be interesting to know at which phase during the first year of fellowship novices reach level of older fellows, as well as how many 24-hour shifts per month are needed to make this learning and acquiring ED-skills faster. In addition, it is highly important to assess areas in which novices' skills and knowledge gaps are most pronounced $[5,7,14,18,20]$.

The results of the present study should be interpreted in the light of several limitations. Firstly, this was a single-centre experience which limits the strength of the observations, however it included data on> 55 fellows who examined more than 19000 patients. Secondly, the findings are difficult to interpret for providers practicing outside of Croatia and are not necessarily applicable outside of the Croatian context. However, Croatia is part of the European Union (EU) and the fellowship program is coordinated with EU's legislation as in most of the European countries. Thirdly, it includes data on 24-hour shifts which is abandoned in many countries; however it could show important medical practice differences (both negative and positive ones).

\section{Conclusion}

To the authors' best knowledge, this is the first report on the ED medical practice differences among internal medicine fellows of different fellowship-year. When compared to other fellows, $1^{\text {st }}$-year fellows participated less in CPR cases and $5^{\text {th }}$-year fellows had the highest proportion of patients admitted to hospital and more CPR cases. This could contribute to the development of educational programs that might help novices improve their skills and consequently their efficiency during early months of their fellowship $[6,10,21]$.

\section{Abbreviations}

CPR - cardiopulmonary resuscitation (CPR)

ED - Emergency Department

EMT - emergency medical team

EU - European Union (EU)

LOS - length of stay (LOS) 


\section{Declarations}

1. Ethics approval and consent to participate: The Sestre milosrdnice University Hospital Ethics Committee gave its approval for the study (Ref. number EP-17395/20-5). Since this was a retrospective study the authors were not obligated to obtain informed consents.

2. Consent for publication: not applicable

3. Availability of data and material: the datasets used and/or analysed during the current study are available from the corresponding author on reasonable request.

4. Competing interests: the authors report no conflict of interest.

5. Funding: the study was conducted without grant support.

\section{Authors' contributions}

MRB: Concept/design, Data analysis/interpretation, Drafting article, Critical revision of article, Approval of article; MKZ: Concept/design, Data analysis/interpretation, Drafting article, Critical revision of article, Approval of article; AB: Concept/design, Data collection, Data analysis/interpretation, Drafting article, Statistics, Critical revision of article, Approval of article; VO: Data collection, Data analysis/interpretation, Drafting article, Approval of article; SR: Data analysis/interpretation, Drafting article, Approval of article; AS: Data collection, Data analysis/interpretation, Drafting article, Approval of article; VR: Data collection, Data analysis/interpretation, Drafting article, Approval of article; NB: Data analysis/interpretation, Critical

revision of article, Approval of article; NP: Data analysis/interpretation, Critical revision of article, Approval of article; KĐ: Data analysis/interpretation, Critical revision of article, Approval of article; SM: Data analysis/interpretation, Drafting article, Critical revision of article, Approval of article; IZ: Concept/design, Data analysis/interpretation, Drafting article, Critical revision of article, Approval of article.

In addition, all authors have read and approved the manuscript.

1. Acknowledgements: The authors are grateful to complete ED staff for helping to collect needed data as well as for patients' care and well-being.

\section{References}

1. http://www.propisi.hr/files/File/Opca_interna_medicina (last accessed: June 2018).

2. Schubert CC, Denmark TK, Crandall B, Grome A, Pappas J (2013) Characterizing novice-expert differences in macrocognition: an exploratory study of cognitive work in the emergency department. Ann Emerg Med. 61:96-109.

3. Verma AA, Guo Y, Kwan JL, Lapointe-Shaw L, Rawal S, Tang T, et al (2017)Patient characteristics, resource use and outcomes associated with general internal medicine hospital care: the General Medicine In patient Initiative (GEMINI) retrospective cohort study. CMAJ Open. 5:E842-E849.

4. Hill RG Jr, Sears LM, Melanson SW (2013) 4000 clicks: a productivity analysis of electronic medical records in a community hospital ED. Am J Emerg Med. 31:1591-4. 
5. Marco CA, Kowalenko T (2015) Emergency medicine residents' perspectives on patient safety and duty hours. Am J Emerg Med. 33:459-60.

6. Bleetman A, Sanusi S, Dale T, Brace S (2012) Human factors and error prevention in emergency medicine. Emerg Med J. 29:389-93.

7. Mache S, Vitzthum K, Klapp BF, Groneberg DA (2012) Doctors' working conditions in emergency care units in Germany: a real-time assessment. Emerg Med J. 29(12):e1.

8. Yau FF, Tsai TC, Lin YR, Wu KH, Syue YJ, Li CJ (2017) Can different physicians providing urgent and non-urgent treatment improve patient flow in emergency department? Am J Emerg Med. pii:S07356757(17)30918-X.

9. Chiu IM, Lin YR, Syue YJ, Kung CT, Wu KH, Li CJ (2018) The influence of crowding on clinical practice in the emergency department. Am J Emerg Med. 36:56-60.

10. Cardona M, O'Sullivan M, Lewis ET, Turner RM, Garden F, Alkhouri H, et al (2018)Reducing prognostic uncertainty in older patients with a checklist for use in emergency departments: a prospective validation study. Acad Emerg Med. doi: 10.1111/acem.13664.

11. Chan SS, Cheung NK, Graham CA, Rainer TH (2015) Strategies and solutions to alleviate access block and overcrowding in emergency departments. Hong Kong Med J. 21:345-52.

12. Lee S, Baek HJ, Jung HK, Moon JI, Cho SB, Choi BH, et al (2017) Interpretations of diffusionweighted MR imaging by radiology residents in the emergency department: is diagnostic performance influenced by the level of residency training? Radiol Med. 122:35-42.

13. Gallagher EJ, Coffey J, Lombardi G, Saef S (1995) Emergency procedures important to the training of emergency medicine residents: who performs them in the emergency department? Acad Emerg Med. 2:630-3.

14. Schenkel SM, Khare RK, Rosenthal MM, Sutcliffe KM, Lewton EL (2003) Resident perceptions of medical errors in the emergency department. Acad Emerg Med. 10:1318-24.

15. Uthman OA, Walker C, Lahiri S, Jenkinson D, Adekanmbi V, Robertson W, et al (2018) General practitioners providing non-urgent care in emergency department: a natural experiment. BMJ Open. 8(5):e019736.

16. Shin S, Lee SH, Kim DH, Kim SC, Kim TY, Kang C, et al (2018) The impact of the improvement in internal medicine consultation process on ED length of stay. Am J Emerg Med.36:620-4.

17. McCarthy ML, Ding R, Pines JM, Zeger SL (2011) Comparison of methods for measuring crowding and its effects on length of stay in the emergency department. Acad Emerg Med.18:1269-77.

18. Kocher KE, Haggins AN, Sabbatini AK, Sauser K, Sharp AL (2014) Emergency department hospitalization volume and mortality in the United States. Ann Emerg Med. 64:446-57.

19. Abualenain J, Frohna WJ, Shesser R, Ding R, Smith M, Pines JM (2013) Emergency department physician-level and hospital-level variation in admission rates. Ann Emerg Med.61:638-43.

20. Sweeney LA, Warren O, Gardner L, Rojek A, Lindquist DG (2014) A simulation-based training program improves emergency department staff communication. Am J Med Qual. 29:115-23. 
21. Calder-Sprackman S, Kumar T, Gerin-Lajoie C, Kilvert M, Sampsel K (2018) Ice cream rounds: The adaptation, implementation, and evaluation of a peer-support wellness rounds in an emergency medicine resident training program. CJEM. 20:777-80.

\section{Tables}

Table 1 Comparison of $1^{\text {st }}$-year fellows' with $5^{\text {th }}$-year fellows' medical practice in Emergency Department during 24-hour shifts

\begin{tabular}{|llll|}
\hline & $\mathbf{1}^{\text {st }}$ year fellows & $\mathbf{5}^{\text {th }}$ year fellows & p value \\
& $\mathrm{N}^{*}=6291$ & $\mathrm{~N}^{*}=4907$ & \\
Age (years) & $62.1 \pm 19.1$ & $60.9 \pm 19.5$ & $\mathbf{0 . 0 0 2}$ \\
Male gender & $45.8(2878)$ & $45.1(2209)$ & 0.467 \\
Brought by out-of-hospital EMT & $27.5(1732)$ & $24.8(1216)$ & $\mathbf{0 . 0 0 1}$ \\
Pts with immobility & $15.3(963)$ & $13.6(666)$ & 0.010 \\
Pts without verbal communication & $3.48(219)$ & $3.71(182)$ & 0.539 \\
Non-conscious patients & $2.53(159)$ & $2.75(135)$ & 0.475 \\
Pts admitted to hospital & $23.8(1500)$ & $25.2(1237)$ & 0.092 \\
Reanimation / CPR cases & $0.11(7)$ & $0.47(23)$ & $<0.001$ \\
Death cases & $0.57(36)$ & $0.39(19)$ & 0.176 \\
Share of pts examined per 24-hour shift & 32.9 & 34.9 & $\mathbf{0 . 0 5}$ \\
Time spent in the ED per patient (min) & $352 \pm 281$ & $360 \pm 280$ & 0.11 \\
\hline
\end{tabular}

*- total number of patients examined by certain group of fellows.

Values are percentage (total number) for categorical and mean \pm standard deviation for continuous variables.

Pts - patients; EMT - Emergency Medical Team; CPR - cardiopulmonary resuscitation; ED - emergency department; min - minutes.

Table 2 Comparison of $1^{\text {st }}$-year fellows' with $2^{\text {nd }}$-year fellows' medical practice in Emergency Department during 24-hour shifts 


\begin{tabular}{|llll|}
\hline & $1^{\text {st }}$ year fellows & $2^{\text {nd }}$ year fellows & p value \\
& $\mathrm{N}^{*}=6291$ & $\mathrm{~N}^{*}=2846$ & \\
Age (years) & $62.1 \pm 19$ & $62.1 \pm 19.5$ & 1 \\
Male gender & $45.8(2879)$ & $45.9(1306)$ & 0.928 \\
Brought by out-of-hospital EMT & $27.6(1734)$ & $33.2(944)$ & $<0.001$ \\
Pts with immobility & $15.2(955)$ & $14.6(415)$ & 0.467 \\
Pts without verbal communication & $3.51(221)$ & $4.04(115)$ & 0.230 \\
Non-conscious patients & $2.57(162)$ & $2.67(76)$ & 0.777 \\
Pts admitted to hospital & $23.8(1498)$ & $24.9(709)$ & 0.257 \\
Reanimation / CPR cases & $0.11(7)$ & $0.46(13)$ & $\mathbf{0 . 0 0 2}$ \\
Death cases & $0.54(34)$ & $0.30(19)$ & 0.459 \\
Share of pts examined per 24-hour shift & 32.97 & 30.36 & $\mathbf{0 . 0 2 9}$ \\
Time spent in the ED per patient (min) & $352 \pm 281$ & $372 \pm 303$ & $\mathbf{0 . 0 0 4}$ \\
\hline
\end{tabular}

*- total number of patients examined by certain group of fellows.

Values are percentage (total number) for categorical and mean \pm standard deviation for continuous variables.

Pts - patients; EMT - Emergency Medical Team; CPR - cardiopulmonary resuscitation; ED - emergency department; $\min$ - minutes.

Table 3 Comparison of $5^{\text {th }}$-year fellows' with all other older fellows' medical practice in Emergency Department during 24-hour shifts 


\begin{tabular}{|llll|}
\hline & $1^{\text {st }}$ year fellows & $2^{\text {nd }}-5^{\text {th }}$ year fellows & p value \\
& $\mathrm{N}^{*}=6291$ & $\mathrm{~N}^{*}=13625$ & \\
Age (years) & $62.1 \pm 19$ & $61.5 \pm 19.5$ & 0.073 \\
Male gender & $45.8(2879)$ & $46.0(6272)$ & 0.725 \\
Brought by out-of-hospital EMT & $27.6(1734)$ & $28.3(3851)$ & 0.309 \\
Pts with immobility & $15.2(955)$ & $14.4(1959)$ & 0.137 \\
Pts without verbal communication & $3.51(221)$ & $3.59(489)$ & 0.804 \\
Non-conscious patients & $2.57(162)$ & $2.33(318)$ & 0.302 \\
Pts admitted to hospital & $23.8(1498)$ & $24.3(3314)$ & 0.444 \\
Reanimation / CPR cases & $0.11(7)$ & $0.37(50)$ & $\mathbf{0 . 0 0 2}$ \\
Death cases & $0.54(34)$ & $0.39(54)$ & 0.166 \\
Share of pts examined per 24-hour shift & 32.97 & 34.24 & 0.108 \\
Time spent in the ED per patient (min) & $352 \pm 371$ & $362 \pm 289$ & $\mathbf{0 . 0 2}$ \\
\hline
\end{tabular}

*- total number of patients examined by certain group of fellows.

Values are percentage (total number) for categorical and mean \pm standard deviation for continuous variables.

Pts - patients; EMT - Emergency Medical Team; CPR - cardiopulmonary resuscitation; ED - emergency department; min - minutes.

Table 4 Comparison of $1^{\text {st }}$-year fellows' with all other younger fellows' medical practice in Emergency Department during 24-hour shifts 


\begin{tabular}{|llll|}
\hline & 5th year fellows & 1st-4th year fellows & p value \\
& $\mathrm{N}^{*}=4907$ & $\mathrm{~N}^{*}=15009$ & \\
Age (years) & $60.9 \pm 19.5$ & $61.9 \pm 19.3$ & $\mathbf{0 . 0 0 1}$ \\
Male gender & $45.1(2209)$ & $46.2(6938)$ & 0.171 \\
Brought by out-of-hospital EMT & $24.8(1216)$ & $29.1(4368)$ & $<0.001$ \\
Pts with immobility & $13.6(666)$ & $15.0(2255)$ & $\mathbf{0 . 0 0 6}$ \\
Pts without verbal communication & $3.71(182)$ & $3.49(524)$ & 0.330 \\
Non-conscious patients & $2.75(135)$ & $2.27(341)$ & $\mathbf{0 . 0 2 7}$ \\
Pts admitted to hospital & $25.2(1237)$ & $23.7(3561)$ & $\mathbf{0 . 0 1 2}$ \\
Reanimation / CPR cases & $0.47(23)$ & $0.23(35)$ & $\mathbf{0 . 0 0 7}$ \\
Death cases & $0.39(19)$ & $0.47(70)$ & 0.454 \\
Share of pts examined per 24-hour shift & 34.87 & 33.48 & 0.152 \\
Time spent in the ED per patient (min) & $360 \pm 280$ & $359 \pm 289$ & 0.881 \\
\hline
\end{tabular}

*- total number of patients examined by certain group of fellows.

Values are percentage (total number) for categorical and mean \pm standard deviation for continuous variables.

Pts - patients; EMT - Emergency Medical Team; CPR - cardiopulmonary resuscitation; ED - emergency department; min - minutes. 